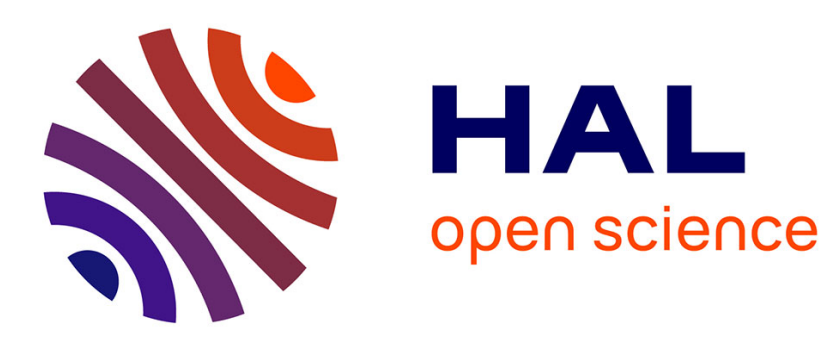

\title{
Life in Burrows Channelled the Morphological Evolution of the Skull in Rodents: the Case of African Mole-Rats (Bathyergidae, Rodentia)
}

Helder Gomes Rodrigues, Radim Šumbera, Lionel Hautier

\section{- To cite this version:}

Helder Gomes Rodrigues, Radim Šumbera, Lionel Hautier. Life in Burrows Channelled the Morphological Evolution of the Skull in Rodents: the Case of African Mole-Rats (Bathyergidae, Rodentia). Journal of Mammalian Evolution, 2015, 23 (2), pp.175-189. 10.1007/s10914-015-9305-x . hal-01196373

\section{HAL Id: hal-01196373 \\ https://hal.sorbonne-universite.fr/hal-01196373}

Submitted on 9 Sep 2015

HAL is a multi-disciplinary open access archive for the deposit and dissemination of scientific research documents, whether they are published or not. The documents may come from teaching and research institutions in France or abroad, or from public or private research centers.
L'archive ouverte pluridisciplinaire HAL, est destinée au dépôt et à la diffusion de documents scientifiques de niveau recherche, publiés ou non, émanant des établissements d'enseignement et de recherche français ou étrangers, des laboratoires publics ou privés. 
Life in burrows channelled the morphological evolution of the skull in rodents: the case of African mole-rats (Bathyergidae, Rodentia).

\section{Authors:}

Helder GOMES RODRIGUES ${ }^{1}$

Radim ŠUMBERA ${ }^{2}$

Lionel HAUTIER ${ }^{3}$

\section{Institutional addresses:}

${ }^{1}$ Present address: Centre de Recherche sur la Paléobiodiversité et les Paléoenvironnements (CR2P), UMR CNRS 7207, CP38, Muséum national d'Histoire naturelle, Univ Paris 6, 8 rue Buffon, 75005 Paris, France.

${ }^{2}$ Department of Zoology, Faculty of Science, University of South Bohemia, Branišovská 31, České Budějovice 37005, Czech Republic.

${ }^{3}$ Laboratoire de Paléontologie, Institut des Sciences de l'Évolution de Montpellier (CNRS, UM, IRD, EPHE), c.c. 064, Université Montpellier, place Eugène Bataillon, 34095 Montpellier Cedex 05, France

\section{Corresponding author:}

Helder Gomes Rodrigues

Email address: helder.gomes.rodrigues@gmail.com

Telephone: +33140793673

Fax: +33140793580 


\section{Abstract}

African mole-rats are fossorial rodents that consist of five chisel-tooth digging genera (Heterocephalus, Heliophobius, Georychus, Fukomys, and Cryptomys) and one scratch digger (Bathyergus). They are characterized by striking physiological, morphological, and behavioral adaptations intimately related to their subterranean life. The influence of their mode of life in shaping the cranial morphology has yet to be evaluated in comparison to other Ctenohystrica, especially fossorial genera, which include the subterranean genera Spalacopus and Ctenomys. In our study, we seek to determine to what extent subterranean life affects the morphofunctional properties of the skull among fossorial ctenohystricans. 3D geometric morphometric analyses were performed on 277 skulls, encompassing 63 genera of Ctenohystrica, and complemented by biomechanical studies. African mole-rats and other subterranean Ctenohystrica, especially chisel-tooth diggers, have a short snout, a wide cranium with enlarged zygomatic arches, and a strongly hystricognathous mandible. Even if convergences are also manifest between most fossorial Ctenohystrica, subterranean rodents departed from the main ctenohystrican allometric trends in having a skull shape less sizedependent, but under stronger directional selection with intense digging activity as a major constraint. African mole-rats, notably chisel-tooth diggers, show important mechanical advantage for the temporalis muscles favoring higher forces at the bite point, while mechanical advantage of the superficial masseter muscles is lower compared to other Ctenohystrica. If subterranean species can be clearly discriminated based on their skull morphology, the intrinsic mosaic of anatomical characters of each genus (e.g., skull, teeth, and muscles) can be only understood in the light of their ecology and evolutionary history.

Keywords: Ctenohystrica, masticatory apparatus, fossorial, subterranean, morphometric geometry, biomechanics 


\section{Introduction}

Among placental mammals, rodents show a very wide range of modes of life (e.g., cursorial, scansorial, jumping, flying, aquatic, fossorial), and this ecological diversity partly explains their blooming evolutionary history. As fossorial rodents do not have the appeal of various more charismatic mammals, in part due to their cryptic lifestyle, they did not attract the interest of researchers until the end of the 70's (e.g., Nevo 1979). However, recent advances in the last decades have enabled a better understanding of the behaviour and the striking biological characteristics of these fascinating rodents (Nevo 1999; Lacey et al. 2000; Begall et al. 2007). Rodents are defined as fossorial when they show specializations for digging (e.g., Lacey et al., 2000). Fossorial rodents are widespread nowadays, and they are present in diverse extant groups, phylogenetically distant, such as the Aplodontidae, Sciuridae, Bathyergidae, Ctenomyidae, Octodontidae, Echimyidae, Geomyidae, Spalacidae and Cricetidae (Arvicolinae and Sigmodontinae). The fossorial lifestyle is more or less developed in rodents. Less specialized fossorial species spend a significant part of their lifetime aboveground, especially for foraging (e.g., some Echimyidae and Cricetidae). Conversely, some rodents show a high fossorial activity (e.g., Bathyergidae, Geomyidae, and some Spalacidae); they spend most of their lifetime underground, including when looking for food and sexual partners, but also to disperse. These species are generally referred to as subterranean (Nevo 1979). In general, fossorial rodents use two main types of digging tools: their strong forearms bearing robust claws for scratching, and/or their prominent and procumbent incisors as a chisel to break up, loosen, and remove the soil. These adaptive characters repeatedly appeared during the rodent evolutionary history.

The first known fossorial rodents probably appeared during the end of the Eocene ( 40 Mya, Matthew and Granger 1923; Nevo 1999; Jardine et al. 2012). This lifestyle became 
more common during the Oligocene, probably because of new types of food resources available and the need of finding alternative shelters in relation to increasing aridity combined with gradual disappearance of forested environments (Nevo 1999; Jardine et al. 2012). Apart from pocket gophers (Geomyidae) and relatives of the mountain beaver (Aplodontoidea), which are among a few extant fossorial groups diversified during the Oligocene epoch (Jardine et al. 2012), the diversity of most of extant groups is the result of recent adaptive radiations (15-5 Mya), such as African mole-rats (Bathyergidae; Cook et al. 2000).

African mole-rats belong to the Ctenohystrica, and comprise species using both main modes of digging (Stein 2000) with five chisel-tooth digging genera (Heterocephalus, Heliophobius, Georychus, Fukomys, and Cryptomys) and one scratch digging genus (Bathyergus). These mole-rats acquired many peculiar morphological, physiological, and behavioral adaptations as a consequence of strict life in subterranean environment (Bennett and Faulkes 2000). Among these adaptations, the most striking ones remain the low basal metabolic rate that likely helped them to compensate high energetic costs of foraging (Zelová et al. 2007), and the high thermal conductance that limits overheating due to activity in humid subterranean environments. Bathyergid rodents also display morphological adaptations related to their strict subterranean life, the most remarkable being the procumbent incisors, and reduced eyes and pinnae (Stein 2000). Interestingly, Heliophobius is one of the rare examples of mammals that shows a continuous dental replacement characterized by the constant development of molars at the back of the jaw, then migrating toward the front (Gomes Rodrigues et al. 2011). This adaptation is likely to be linked to strong dental wear partly due to the impossibility to use cooperative digging strategies combined with a high chisel-tooth digging activity in different soils, which could be extremely hard during the dry season (Gomes Rodrigues et al. 2011). As most of physiological and anatomical characteristics of bathyergids are deeply influenced by their subterranean lifestyle, we seek to 
determine to what extent the cranial morphology and the associated mechanics of masticatory muscles were impacted in these rodents compared to their relatives.

The masticatory apparatus of rodents is a highly plastic region of the skull, and some studies have already shown that its shaping shows a significant ecological component driven by factors such as habitat and feeding habit (Michaux et al. 2008; Hautier et al. 2012; Casanovas-Vilar and Van Dam 2014; Renaud et al. 2015). Our aim is to evaluate cranial and mandibular variations between African mole-rats and other Ctenohystrica in order to assess the influence of phylogenetic and size components on skull morphology. Variations have also been measured within African mole-rats in relation to their digging skills. Finally, we focused on the morpho-functional properties of the masticatory apparatus to draw comparisons between fossorial Ctenohystrica based on their mode of digging and their foraging activity (see Table 1).

\section{Material and methods}

Sample composition

The database compiled by Hautier et al. (2012) has been complemented by new material of Ctenohystrica from the Natural History Museum in London (NHM). We analyzed 246 mandibles and 277 crania belonging to rodents of both sexes (but data are frequently missing), representing 63 genera and 17 families of Ctenohystrica (Table 1, Online resource 1), and most of bathyergid genera were added. Bathyergids were not investigated in Hautier et al. $(2011,2012)$ because their peculiar cranial morphology precludes the retrieval of some of the landmarks defined on the crania and mandibles. Cryptomys was not considered here; however, this genus is very close to Fukomys in shape (in fact Fukomys was recently split 
from Cryptomys sensu lato based mainly on genetic data; see Kock et al. 2006 for further details). In our study, African mole-rats (Bathyergidae), Spalacopus (Octodontidae) and Ctenomys (Ctenomyidae), which have a prevailing subterranean activity (see Table 1), were designated as subterranean rodents (sensu Nevo, 1979).

Geometric morphometric methods

The mandibular and cranial forms were quantified with 19 and 59 anatomical landmarks, respectively (Fig. 1 and Online resource 2). Digital data of all specimens were acquired using a Microscribe 3-D digitizer and using X-ray micro-computed tomography $(\mu \mathrm{CT})$. One skull of Heliophobius (ID 13) was scanned using a GE phoenix nanotom 180 at energy of $100 \mathrm{keV}$ with a cubic voxel of $22.727 \mu \mathrm{m}$, in order to visualize virtual deformations within the bathyergid dataset, while a scan of Proechimys (see Hautier et al. 2011, 2012) was used for Ctenohystrica. Because the mandible of rodents is constituted of a unique dentary bone of relatively simple shape, most of the landmarks taken on the dentary were of type 2 (e.g., maxima of curvature - Fig. 2; Bookstein 1991). All configurations (sets of landmarks) were superimposed using the Procrustes method of generalized least squares superimposition (GLS scaled, translated, and rotated configurations so that the intralandmark distances were minimized) following the method used by Rohlf (1999) and Bookstein (1991). Subsequently, mandibular and cranial forms of each specimen were represented by centroid size $S$, and by multidimensional shape vector v in linearized Procrustes shape space. Shape variability of the cranium and mandible was analyzed by principal components analyses (PCA) of shape (Dryden and Mardia 1998). Analysis and visualization of patterns of shape variation were performed with the interactive software package MORPHOTOOLS (Specht et al. 2007; Lebrun et al. 2010). A public version is currently being developed (contact 
renaud.lebrun@univ-montp2.fr for further information). A multivariate regression of the first 35 PCs (95\% of the variance) on size, estimated by the logarithm of the centroid size, allowed us to take into account the potentially confounding effects of size allometry on shape. Additionally, univariate regressions were realized using the first two principal components and the logarithm of the centroid size of each specimen. We conducted separate regression analyses for both bathyergids and non-bathyergid Ctenohystrica in order to search for size trends within these groups; differences in slope were tested using ANCOVA. Multivariate regressions and ANCOVAs were performed with Past 2.06 (Hammer et al. 2001). To account for the influence of phylogeny on our result, we regressed phylogenetically independent contrasts (PICs; Felsenstein 1985) to test whether the size (log centroid size) and shape components (i.e., PC1 to 3) show evidence of correlated evolution. The phylogeny used in the PIC analysis derived from Fabre et al. (2012). PIC analysis was implemented using the PDAP:PDTREE module, version 1.14 (Midford et al. 2008) of Mesquite, version 2.71 (Maddison and Maddison 2009).

Furthermore, covariation patterns between the crania and the mandibles were studied using 2-blocks partial least square analysis, as described by Bookstein et al. (2003), only adapted to allow for the use of 3D landmarks. For the $\mathrm{N}=237$ specimens for which both cranial $(\mathrm{k}=59)$ and mandibular $(\mathrm{l}=19)$ landmarks had been digitized, cranial and mandibular landmark configurations were aligned separately using GLS, yielding a cranial matrix of $\mathrm{N}^{*}$ $3 \mathrm{k}$ shape coordinates and a mandibular matrix of $\mathrm{N} * 31$ shape coordinates. The PLS analysis computed a series of pairs of unit vectors, the singular cranial and mandibular warps (Uc and $\mathrm{Um}$ ), each being of length $3 \mathrm{k}$ and 31 , respectively. These pairs of singular warps maximize the covariance between the two sets of shape coordinates. Cranial and mandibular projection scores of the specimens on the singular warps were subsequently computed. 


\section{Biomechanical analyses}

They allow the quantification of the mechanical advantage of each adductor muscle (i.e., temporalis, supercifial masseter, and deep masseter) by measuring the force transmitted from the muscle to the bite point (i.e., incisor and cheek teeth). It can be estimated as the ratio of the inlever (distance from the condyle or fulcrum to the point of muscle attachment) and the outlever (distance from the condyle to the bite point; Hiiemae 1971). Three adductor muscles have been considered for inlevers: the temporalis that attaches on the coronoid process (landmarks 64 and 73), the superficialis masseter that attaches along the angular process (landmarks 68 and 77), and the deep masseter that attaches on the masseteric crest (landmarks 69 and 78) (Baverstock et al. 2013; Renaud et al. 2015). Rodents are characterized by two dental regions that were alternatively considered for outlevers: the incisors, used for gnawing isolated from the cheek teeth, used for chewing. Unfortunately, the bite point at the tip of the incisor could not be used, because of large intraspecific variation due to wear (see CasanovasVilar and Van Dam 2013). Thus, no interpretation could be made on the incisor procumbency. Consequently, the landmark (60), located at the posterior part of the alveolar margin of incisor, was used for the outlever. Six estimates of biomechanical advantage (inlever/outlever) were thus considered for a given mandible: T/I (temporalis/incisor), SM/I (superficial masseter/incisor), DM/I (deep masseter/ incisor), T/CT (temporalis/cheek teeth), SM/CT (superficial masseter/cheek teeth), and DM/CT (deep masseter/cheek teeth). Differences between bathyergids in the inlever/outlever ratios were tested using post-hoc multiple mean comparison tests: the Fischer's Least Significant Difference test (LSD) and the Tukey's Honestly Significant Difference test (HSD), the latter being less sensitive but more conservative than the former (Online resource 3). 


\section{Results}

Comparison of skull shape among Ctenohystrica

According to both PCAs performed on the whole dataset, bathyergids can be clearly discriminated from other non-fossorial or fossorial ctenohystricans (Fig. 2). The crania of fossorial rodents plot on the positive side of PC1, with bathyergid rodents on the most positive values. Among non-bathyergid subterranean Ctenohystrica, Spalacopus and Ctenomys plot in the vicinity of bathyergids, and more generally, chisel-tooth diggers show the most distinctive shape. Fossorial rodents, especially subterranean forms, are characterized by a short and wide cranium having a wide snout, but large zygomatic arches, small incisive foramina (landmarks 27-28 and 46-47), a narrow frontal area, a dorsal part of squamosal bone more developed, and an elevated and laterally extended occipital region. This shape clearly departs from the cranial morphology of non-fossorial rodents, which have a gracile and elongated cranium with an extended fronto-parietal area, a low cranial height and an occipital part protruding backward (Fig. 2a). PC2 discriminates species with enlarged snout and a narrow braincase from species with short and gracile snout and a large braincase (Fig. 2a).

For mandibles, Ctenomys plots with bathyergids on the positive values of PC1 (Fig. 2b). All these species are characterized by a short mandible, a strong hystricognathous condition, with enlarged coronoid and reduced condylar processes. These morphological trends are here again more pronounced in the chisel-tooth diggers. On the negative values of PC2, some taxa (e.g., Bathyergus) show an elongated mandible with elongated angular processes and reduced condyle, compared to other scratch diggers, which have more developed condylar and reduced angular processes.

A multivariate regression of the shape component on size, estimated by the logarithm 
of centroid size, was highly significant (mandible: $\mathrm{F}=28.16, \mathrm{p}<0.001$, $\mathrm{df}=213$; cranium: $\mathrm{F}=86.61, \mathrm{p}<0.001, \mathrm{df}=245)$. As such, allometry therefore explains a substantial part of shape variation, and plays an important role in determining the pattern of morphological differentiation of the skull. The Phylogenetic Independent Contrasts (PIC) analysis is congruent with these results, and indicates that after phylogenetic correction, allometry plays a crucial role in determining the pattern of morphological differentiation of the cranium (PC1, $\left.\mathrm{r}^{2}=0.08 ; p=0.03 ; \mathrm{PC} 2, \mathrm{r}^{2}=0.52 ; p=1.4 \times 10^{-10}\right)$ and the mandible $\left(\mathrm{PC} 1, \mathrm{r}^{2}=0.31 ; p=4.4 \times 10^{-6}\right.$; PC2, $\left.\mathrm{r}^{2}=0.18 ; p=7.5 \times 10^{-4}\right)$. The regression of the first mandibular and cranial PCs on centroid size (Fig. 3a and b) shows that most fossorial Ctenohystrica are of very small size (e.g., Heterocephalus). However, some of the less specialized fossorial species (Lagostomus, Myocastor) have larger skulls. When PC2 are regressed against the centroid size, bathyergid rodents (especially chisel-tooth diggers like Heterocephalus) and other subterranean genera (Spalacopus and Ctenomys) clearly depart from the regression lines, which corresponds to the main trends observed in Ctenohystrica (see Hautier et al. 2012). ANCOVAs indicate significant differences in the slope between the crania of bathyergid and non-bathyergid Ctenohystrica $\left(\mathrm{PC} 1, \mathrm{~F}=6.85, p=0.009 ; \mathrm{PC} 2, \mathrm{~F}=6113.7, p=1.8 \times 10^{-22}\right.$ ). In contrast, there are no significant differences in the slope when considering their mandibles ( $\mathrm{PC} 1, \mathrm{~F}=2.144, p=0.14$; $\mathrm{PC} 2, \mathrm{~F}=18.69, p=0.67)$.

Covariation evidently exists between cranium and mandible in Ctenohystrica, and underscores the differences observed between the skull shape of non-fossorial species and fossorial rodents, bathyergids in particular $\left(\mathrm{r}^{2}=0.78, p=4.3 \times 10^{-80}\right.$; Fig. 4). Covariation patterns are different between chisel-tooth diggers and scratch diggers, in both bathyergids and other fossorial Ctenohystrica. Here again, a few bathyergid genera (Heliophobius, and both Fukomys species) set apart from the general regression on SW1, and an ANCOVA shows significant differences in the slope between the skull of bathyergids and non-bathyergid 
Ctenohystrica on $\mathrm{SW} 1\left(\mathrm{~F}=45.27, p=1.29 \times 10^{-10}\right)$. A relation is also present on $\mathrm{SW} 2\left(\mathrm{r}^{2}=0.66\right.$; $\left.p=5 \times 10^{-59}\right)$, but it is weaker and poorly informative regarding the comparison of fossorial and non-fossorial ctenohystricans.

Comparison of the lever arm lengths between fossorial and non-fossorial Ctenohystrica

As expected, the results are slightly different whether we considered the incisors or the cheek teeth as the outlever. Except for Heterocephalus and Heliophobius, chisel-tooth diggers tend to show high values of lever arm ratios for the temporalis muscle (Fig. 5; incisor and cheek teeth). In contrast, chisel-tooth digging bathyergids are characterized by low values of ratios for the superficial masseter (Fig. 5; incisor and cheek teeth). Bathyergus always shows higher values than other bathyergids, and so do Spalacopus and Ctenomys. Whatever the outlever considered for the superficial masseter, scratch diggers are always characterized by high values of ratios, while non-fossorial rodents mostly sit in the middle of the graph. The results for the deep masseter are more difficult to interpret because of the really low variation range of the arm ratios for this muscle (Fig. 5), and no clear pattern of differentiation emerges in relation to the different digging modes. When focusing on mole-rats, statistical tests reveal that African mole-rats present significant differences regarding most inlever/outlever ratios (Online resource 3). In contrast, F. mechowii and Georychus do not show any significant differences. Interestingly, both taxa show highly significant differences with $F$. vandewoestijneae only for the deep masseter, and with Bathyergus only for the superficial masseter. Heliophobius and Heterocephalus only display slight significant differences when the outlever arm of the molars is considered, with higher ratios for Heliophobius. However, both genera show strong differences with most of other bathyergids. 
Comparison of skull shape among the Bathyergidae

The principal component analyses clearly demonstrate that chisel-tooth diggers and scratch diggers (i.e., Bathyergus) show distinct crania and mandibles (Fig. 6a). On PC1, Heterocephalus sets apart from other mole-rats on the negative values in having a larger braincase, a shorter snout, and reduced jugal bones, while the maxillaries are enlarged at the level of the zygomatic arches. The second component clearly separates scratch diggers from chisel-tooth diggers. Bathyergus shows a more slender cranium with an elongated snout, and a lower cranial height. On the third principal component, Heliophobius plots on the negative values and differs from other mole-rats in having a smaller braincase, a reduced snout, but wider zygomatic arches and a shorter tooth row.

Mandible shapes of scratch and chisel-tooth diggers are clearly separated on PC1 (Fig. 6b). Bathyergus shows an elongated mandible with enlarged angular and reduced coronoid processes, while other mole-rats have a shorter mandible with more developed coronoid and reduced angular processes.

\section{Discussion}

Convergent morphological trends in fossorial Ctenohystrica

Clear morphological trends have been observed between fossorial and non-fossorial Ctenohystrica. Both the mandible and cranium showed a strong imprint of the different degrees of fossoriality observed among Ctenohystrica. However, the mandible, with its simple morphology, appears to be more prone to convergent evolution because non-related groups with similar ecology sat closer to each other in the mandibular morphospace (e.g., chisel tooth 
diggers). Subterranean rodents have a short and wide skull, especially chisel-tooth diggers, and this morphology is frequently associated with change in body size. A small size favors the life underground because the costs of burrowing generally increase with body size (Vleck 1981). We showed that the more fossorial the species are (e.g., subterranean forms), the more these morphological characters are pronounced. Conversely, less specialized fossorial species (e.g., Lagostomus, Myocastor) are usually bigger precluding an exclusive life underground. The skull is generally less constrained in scratch diggers, which have larger skull and body size. In subterranean species such as Ctenomys, Spalacopus, and bathyergids, the convergent acquisition of enlarged zygomatic arches and squamosal bones, where the adductor muscles attach, is clearly linked to strong fossorial adaptations. Similarities are also observed at the level of the mandibular ramus of these species, in which the articular condyle is generally less protruding than the coronoid and/or angular processes, allowing large insertions for adductor muscles. This kind of configuration is frequently present in other fossorial rodents, especially in some Spalacidae (Stein 2000), and already occurred in one of the first known fossorial Ctenohystrica, Tsaganomys altaicus from the Oligocene of Mongolia (Bryant and McKenna 1995). But in spite of appearances, the rough skull similarities observed among the investigated fossorial rodents should not conceal the fact that different associations of morphological features exist for a given digging mode (e.g., Ctenomys, Spalacopus, and African mole-rats).

The special case of African-mole rats

Evolutionary trends associated with cranial shape in Bathyergidae do not match those observed in most fossorial and non-fossorial Ctenohystrica. Even if a size reduction appears to be a prerequisite for living underground, it did not totally constrain the shaping of the skull 
in bathyergids as it did in most Ctenohystrica, except for subterranean rodents (Spalacopus and Ctenomys). African mole-rats clearly depart from most Ctenohystrica in showing highly derived cranial and mandibular morphologies. This is notably shown by chisel-tooth diggers (e.g., Heterocephalus, Fig. 3), which have reduced and rounded angular processes, as well as pronounced pterygoid processes associated with a very backward origin of the alveolus of the upper incisors, which are much more procumbent. The relative morphological isolation of African mole-rats explains why their phylogenetical relationships have been the subject of a longstanding debate over the past century (Tullberg 1899; Ellerman 1940; Landry 1957; de Graaff 1979). Bathyergid skulls show more resemblances with other subterranean rodents, such as Spalacopus and Ctenomys, than with their sister taxa Thryonomys and Petromus. Their unique morphology highlights a deep ecological component, which is due to strict life underground associated with a prolonged use of incisor for digging. As a result, the skull of bathyergids underwent strong directional selection related to their singular ecology, which allows them to depart from the morphological pathways that ruled the evolution of most Ctenohystrica and were more tightly coupled to allometric variations (Hautier et al. 2012). These morphological modifications might have partly been favoured by the miniaturisation of the eyes, as it is usually the case in strict subterranean species (e.g., some mole-rats), or to changes in their positioning on the skull roof in subterranean species having also aboveground activity (e.g., Ctenomys and Spalacopus; Stein 2000). Because the position of the eye was suggested as one of the limiting factor determining the morphological evolution of the masticatory apparatus in Ctenohystrica (Hautier et al. 2012), a relaxed selection on this character might have released some room for the development of adductor muscles (Cox and Faulkes 2014).

Masticatory mechanics of the main digging groups 
All chisel-tooth digging bathyergids except Bathyergus are characterized by shorter mandibles with elongated coronoid, rounded angular processes, and masseteric crests placed anteriorly, and this will have a major impact on the biomechanics of the jaw. The mandibular morphology in Bathyergus rather resembles the association of features found in other digging hystricognaths that show elongated angular and reduced coronoid processes. This is probably related to its scratch digging behavior associated with life in soft sandy soils (Bennett et al. 2009), relaxing constraints on the skull as in most non-bathyergid fossorial species compared to chisel-tooth diggers that generally dig in harder soils. Mole-rats have been shown to be forceful biters that can exert bite forces higher than expected for a mammal of comparable body size, especially at the level of molars (Van Daele et al. 2009). This is partly favored by the "most freely moveable jaws of any rodent" (Landry 1957) allowed by unfused symphysis between the two halves of the mandible, and enlarged and flat glenoid fossa (de Graaff 1979). Only a few descriptions of the masticatory musculature of bathyergids can be found in the literature, most of them just briefly mentioned the specific nature of their myology (Tullberg 1899; Morlok 1983; Van Daele et al. 2009; Cox and Faulkes 2014). Nonetheless, interesting comparisons of masticatory muscles have recently been drawn between subterranean, less fossorial, and non-fossorial ctenohystricans (Ctenomys, Octodon, and Chinchilla, respectively; Becerra et al. 2014). The mechanics of the masticatory apparatus are complex because each muscle acts with a different lever advantage; some muscles are specialized for large speed and some for large force (Kardong 2006). The mechanics of lever implie that output force and output speed work in opposite directions: short output lever arms relative to input lever arms favoring force while long output lever arms favor speed (Kardong 2006).

In Heterocephalus, the temporalis represents the largest jaw-closing muscle (Cox and Faulkes 2014), and this muscle seems to dominate the masticatory musculature in all other 
bathyergids (Morlok 1983; Tullberg 1899; Van Daele et al. 2009). Druzinski (2010) suggested that the enlargement of the temporalis may result from the widening of the skull commonly observed in fossorial species. A large temporalis is likely to produce substantial forces at the teeth (Hiimae 1971). Mechanical advantages of the input lever arms of the temporalis were rather variable across the different digging types (Fig. 5) and no clear pattern emerged to distinguish chisel-tooth diggers from scratch diggers. Yet, most of the bathyergids and fossorial caviomorphs showed high value of the ratio when the incisors were considered as the outlever. Such a result can be partly explained by a combination of a shortening of the mandible, especially the diastema, and an elongation of the coronoid process, which produces the reduction of the output lever arm of the jaw-closing muscles and, in turn, an increase of the mechanical advantage for the temporalis (i.e., inlever $\mathrm{T}$ larger relative to outlever I). By moving the output closer to the fulcrum, the temporalis muscle can create more output force at the level of the incisors. However, the fact that we measured the outlever at the anterodorsal edge of the incisor alveolus instead of its tip surely had an impact on the results as the output is displaced closer to the fulcrum.

In the naked mole-rat, the superficial and deep masseters together represent almost $50 \%$ of the masticatory musculature and are likely to deliver high bite force especially at the level of the cheek teeth (Cox and Faulkes 2014). The superficial masseter is reduced laterally and wraps around the ventral margin of the mandible; it shows a really large pars reflexa. Its strong horizontal component implies that it probably acts as the main protractor of the mandible (Cox and Faulkes 2014). Due the high position of the landmarks defining the angular process (Landmarks 68 and 77, Fig. 1b and d), which is close to the condyle (i.e., inlever SM smaller relative to outlever I), the tooth digging bathyergids always showed the lowest values of ratios. Lever arms of the superficial masseter are less favorable to force output in the mandible of the bathyergids but more favorable to speed. Compared to the small 
input lever arm defined between the condyle and the angular process, the relatively greater output lever arm increases the speed at the expense of the output force. By moving the input force closer to the fulcrum, the superficial muscle can generate higher output speed. In contrast to the clear-cut results obtained for the superficial masseter, the lever arm ratios of the deep masseter were not significantly different between rodents of different modes of digging (Fig. 5).

The temporalis and the superficial masseter show opposite mechanical advantages and make different contribution to force and speed output. The temporalis ratio favors force, which is important during chisel-tooth digging, while the superficial masseter has a mechanical advantage favoring velocity.

Cranial evolution in African mole-rats

In addition to the main morphological characters related to fossorial life that best characterize African mole-rats, significant divergences can be observed among them. The skull of Bathyergus strongly differs from other mole-rats in being more elongated. The enlarged snout associated with a gracile skull can be related to the fact that Bathyergus mainly uses its foreclaws for digging in soft sandy soils, contrary to most mole-rats living in hard soils that use their incisors and have strongest masticatory muscles. However, Bathyergus still shows a high masticatory effectiveness, notably at the level of cheek teeth. This is in line with the fact Bathyergus has high-crowned cheek teeth. Despite the fact that they show obvious differences in cranial shape, Bathyergus and its sister genus Georychus display close biomechanical affinities, especially regarding the deep masseter and the temporalis. Bathyergus also shows the same affinities with $F$. mechowii, the largest Fukomys species that is able to construct very large burrow systems (Šumbera et al. 2012). More generally, the mosaic of cranial and 
mandibular characters of Bathyergus can be regarded as intermediate between the Ctenohystrica and Bathyergidae. However, this does not imply that Bathyergus can be considered as a putative ancestral bathyergid skull shape. The oldest bathyergid skulls known in the fossil record (Lavocat 1973; Mein and Pickford 2008) are more similar to those of Heterocephalus and Heliophobius, which belong to ancient lineages (Faulkes et al. 2004; Van Daele et al. 2007; Patterson and Upham 2014). Even if Bathyergus presents primitive characters, such as the connection between the pterygoid fossa and the orbit as in most Ctenohystrica (Landry 1957), this connection is already present in ancestral forms with short and wide cranium, such as Renefossor ${ }^{\dagger}$ and Proheliophobius ${ }^{\dagger}$ (Lavocat 1973). Moreover, in most Miocene taxa (e.g., Bathyergoides ${ }^{\dagger}$, Renefossor ${ }^{\dagger}$ Proheliophobius $^{\dagger}$, Efeldomys ${ }^{\dagger}$ ), the infraorbital foramina are not reduced like in extant species. In Efeldomys ${ }^{\dagger}$, the incisive foramina are also longer than in all extant bathyergids, including Bathyergus (Lavocat 1973; Mein and Pickford 2008). Consequently, the skull shape of Bathyergus should by no means be seen as ancestral. It presents an association of derived features, some of which evolved convergently in Ctenomys and Spalacopus. Bathyergus probably derived from a basal stock of mole-rats that was already strongly adapted to fossorial life, and for which putative active chisel-tooth diggers have been recognized based on the presence of procumbent incisors (e.g., Renefossor $^{\dagger}$ and Proheliophobius ${ }^{\dagger}$; Lavocat 1973).

Heterocephalus belongs to an early diverging lineage of Ctenohystrica (Patterson and Upham 2014), and is a highly derived genus, in terms of morphological and biological characters. However, it is difficult to explain why Heterocephalus has an enlarged braincase. This braincase enlargement might simply be due to allometric constraints since most small ctenohystricans tend to show relatively larger braincase (Hautier et al., 2012). Whatever the cause, this character is probably not related to the social behavior of Heterocephalus because other social mole-rats, such as Fukomys, do not have an enlarged skull. Contrary to 
Heterocephalus, Heliophobius only slightly differs from other mole-rats, and has a small braincase and a wider skull, which permit optimizing the area of attachment and the strength of adductor muscles. The digging activity of this solitary species, which is capable of removing hard soil and constructing extensive burrows (Barčiová et al. 2009), surely had a major impact on the evolution of its cranial morphology, including their unique continuous dental replacement. Even if Heliophobius presents a mechanical advantage for its adductor muscles lower than most mole-rats, it comparatively and relatively shows higher output forces at the level of molars, meaning that a very strong resulting pressure can be exerted at this level. High output force on molars can also contribute to the high wear affecting the dentition due to high abrasion during eating and also due to high attrition during chisel-tooth digging in hard soils. We showed that the dental length in Heliophobius is also reduced compared to most mole-rats, so a continuous dental replacement constitutes a suitable means to maintain a functional dentition. In Heterocephalus, the reduced output force on molars is compatible with the observed reduction of their dentition, which does not need a superimposed adaptation to fight wear, not even very high-crowned teeth.

We have demonstrated that the skull of mole-rats, and more generally, of subterranean rodents, is strongly and historically influenced by the nature of their fossorial activity, which in turn minimizes the size effect. It cannot be assumed that the evolution of their skulls was shaped by the intensity of digging activity, inasmuch as records of daily energetic expenditure in social and solitary mole-rats are quite similar (Zelová et al. 2011). It cannot be either proposed that their skull morphology is strongly influenced by their social or solitary behaviour, because the solitary Georychus and the social Fukomys species display close cranial morphologies, while they probably diverged about 10-15 Mya (Patterson and Upham 2014). Nonetheless, social polymorphism and sexual dimorphism (e.g., Bathyergus suillus, Hart et al. 2007; Fukomys mechowii, Chimimba et al. 2010) could explain some parts of the 
intraspecific variation, alongside the variations observed between populations of African mole-rat species living in different environments. Previous studies showed that skull shape of Ctenohystrica is indeed plastic and highly sensitive to the environments, and that the soil hardness and compactness can have a significant impact on its evolution (Vassallo 1998; Mora et al. 2003; Barčiová et al. 2009). Consequently, the different digging strategies in African mole-rats will be more accurately understood when placed in the climatic and environmental context of their origins, since their local adaptations and their current habits only reflect shaded parts of their evolutionary history.

\section{Acknowledgments}

We are grateful to R. Portela Miguez from the National History Museum of London, and to P. Mein from the Universite Lyon 1 for providing access to their collections of rodents. We thank R. Lebrun (Institut des Sciences de 1'Evolution de Montpellier) who kindly gave us access to MeshTools and Morphotools, and for his help during analyses, and to P.-H. Fabre (Institut des Sciences de 1'Evolution de Montpellier) who allowed us to use his phylogenetic data on Ctenohystrica for PIC analyses. We also acknowledge P. Cox and A. McIntosh (Hull York Medical School) for fruitful discussions on African mole-rats and associated musculatures. Thanks to C. Charles (Institut de Génomique Fonctionnelle de Lyon, Structure Fédératrice de Recherche BioSciences UMS3444/US8, Gerland - Lyon Sud) for giving access to facilities associated with X-ray microtomography. The manuscript benefited from the constructive comments of two anonymous reviewers, and of the editor-in-chief, John Wible. This work was supported by La Fondation des Treilles (www.les-treilles.com, grant to H.G.R.), and by the Grant Agency of Czech Republic, n. 41-14-36098G (R.S.). 


\section{Compliance with Ethical Standards}

The authors declare that they have no conflict of interest. This article does not contain any studies with human participants or animals performed by any of the authors. Informed consent was obtained from all individual participants included in the study.

\section{References}

Barčiová L, Šumbera R, Burda H (2009) Variation in the digging apparatus of the subterranean silvery mole-rat, Heliophobius argenteocinereus (Rodentia, Bathyergidae): the role of ecology and geography. Biol J Linn Soc 97:822-831

Baverstock H, Jeffery NS, Cobb SN (2013) The morphology of the mouse masticatory musculature. J Anat 223:46-60

Becerra F, Echeverri AI, Casinos A, Vassallo AI (2014) Another one bites the dust: bite force and ecology in three caviomorph rodents (Rodentia, Hystricognathi). J Exp Zool 9999:1-13

Begall S, Burda H, Schleich CE (2007) Subterranean Rodents: News from Underground. Springer, Berlin, Heidelberg, New York

Bennett NC, Faulkes CG (2000) African Mole-rats: Ecology and Eusociality. Cambridge University Press, Cambridge

Bennett NC, Faulkes CG, Hart L, Jarvis JUM (2009) Bathyergus suillus (Rodentia: Bathyergidae). Mammal Species 828:1-7

Bookstein FL (1991) Morphometric Tools for Landmark Data Geometry and Biology. Cambridge University Press, Cambridge

Bookstein FL, Gunz P, Mitteroecker P, Prossinger H, Schaefer K, Seidler H (2003) Cranial integration in Homo: singular warps analysis of the midsagittal plane in ontogeny and evolution. J Hum Evol 44:167-187 
Bryant JD, McKenna MC (1995) Cranial anatomy and phylogenetic position of Tsaganomys altaicus (Mammalia: Rodentia) from the Hsanda Gol Formation (Oligocene), Mongolia. Am Mus Novitates 3156:1-42

Casanovas-Vilar I, Van Dam J (2013) Conservatism and adaptability during squirrel radiation: what is mandible shape telling us? PLoS ONE 8:e61298

Chimimba CT, Sichilima AM, Faulkes CG, Bennett NC (2010) Ontogenetic variation and craniometric sexual dimorphism in the social Giant mole-rat, Fukomys mechowii (Rodentia: Bathyergidae), from Zambia. Afr Zool 45:160-176

Cook JA, Lessa EP, Hadly EA (2000) Paleontology, phylogenetic patterns, and macroevolutionary processes in subterranean rodents. In: Lacey EA, Patton JL, Cameron GN (eds) Life Underground: The Biology of Subterranean Rodents. University of Chicago Press, Chicago, pp 332-369

Cox PG, Faulkes CG (2014) Digital dissection of the masticatory muscles of the naked molerat, Heterocephalus glaber (Mammalia, Rodentia). PeerJ 2:e448

Druzinsky RE (2010) Functional anatomy of incisal biting in Aplodontia rufa and sciuromorph rodents. Part 1: masticatory muscles, skull shape and digging. Cells Tissues Organs 191:510-522

Dryden IL, Mardia KV (1998) Statistical Shape Analysis. Wiley, Chichester

Ellerman JR (1940) The Families and Genera of Living Rodents. Vol. 1: Rodents other than Muridae. British Museum (Natural History), London

Fabre P-H, Hautier L, Dimitrov D, Douzery E (2012) A glimpse on the pattern of rodent diversification: a phylogenetic approach. BMC Evol Biol 12:1-19

Faulkes CG, Verheyen E, Verheyen W, Jarvis JUM, Bennett NC (2004) Phylogeographical patterns of genetic divergence and speciation in African mole-rats (Family: Bathyergidae). Mol Ecol 13:613-629 
Felsenstein J (1985) Phylogenies and the comparative method. Am Nat 125:1-15

Gomes Rodrigues H, Marangoni P, Šumbera R, Tafforeau P, Wendelen W, Viriot L (2011) Continuous dental replacement in a hyper-chisel tooth digging rodent. Proc Natl Acad Sci USA 108:17355-17359

de Graaff G (1979) Molerats (Bathyergidae, Rodentia) in South African national parks: notes on the taxonomic "isolation" and hystricomorph affinities of the family. Koedoe 22:89-107

Hammer $\varnothing$, Harper DAT, Ryan PD (2001) PAST: paleontological statistics software package for education and data analysis. Palaeontol Electron 4:9

Hart L, Chimimba CT, Jarvis JUM, O'Riain Justin, Bennett NC (2007). Craniometric sexual dimorphism and age variation in the South African Cape dune mole-rat (Bathyergus suillus). J Mammal 88:657-666

Hautier L, Lebrun R, Cox PG (2012) Patterns of covariation in the masticatory apparatus of hystricognathous rodents: implications for evolution and diversification. J Morphol 273:1319-1337

Hautier L, Lebrun R, Saksiri S, Michaux J, Vianey-Liaud M, Marivaux L (2011) Hystricognathy vs sciurognathy in the rodent jaw: a new morphometric assessment of hystricognathy applied to living fossil Laonastes (Rodentia, Diatomyidae). PLoS ONE 6:e18698

Hiiemae K (1971) The structure and function of the jaw muscles in the rat (Rattus norvegicus L.) III. The mechanics of the muscles. Zool J Linn Soc 50:111-132

Jardine PE, Janis CM, Sahney S, Benton MJ (2012) Grit not grass: concordant patterns of early origin of hypsodonty in Great Plains ungulates and Glires. Palaeogeogr Palaeoclim Palaeoecol 365-366:1-10

Kardong K (2006) Vertebrates - Comparative Anatomy, Function, Evolution, Fourth edition. 
McGraw-Hill, New York

Kock D, Ingram CM, Frabotta LJ, Honeycutt RL, Burda H (2006) On the nomenclature of Bathyergidae and Fukomys N. Gen. (Mammalia: Rodentia). Zootaxa 1142:51-55

Lacey EA, Patton JL, Cameron GN (2000) Life Underground: The Biology of Subterranean Rodents. University of Chicago Press, Chicago

Landry SC (1957) The interrelationships of the New and Old World hystricomorph rodents. Univ Calif Pub Zool 56:1-118

Lavocat R (1973) Les rongeurs du Miocène d'Afrique Orientale I. Miocène inférieur. Mém Trav EPHE, Inst Montpellier 1:1-284

Lebrun R, Ponce de León MS, Tafforeau P, Zollikofer CPE (2010) Deep evolutionary roots of strepsirrhine primate labyrinthine morphology. J Anat 216:368-380

Maddison WP, Maddison DR (2009) Mesquite: a modular system for evolutionary analysis. http://mesquiteproject.org

Matthew WD, Granger W (1923) New Bathyergidae from the Oligocene of Mongolia. Am Mus Novitates 101:1-5

Mein P, Pickford M (2008) Early Miocene Rodentia from the northern Sperrgebiet, Namibia. Mem Geol Sur Namibia 20:235-290

Michaux J, Hautier L, Simonin T, Vianey-Liaud M (2008) Phylogeny, adaptation and mandible shape in Sciuridae (Rodentia, Mammalia). Mammalia 72:286-296

Midford PE, Garland Jr T, Maddison WP (2008) PDAP-PDTREE Package for Mesquite. http://mesquiteproject.org/pdap_mesquite/

Mora M, Olivares AI, Vassallo AI (2003) Size, shape and structural versatility of the skull of the subterranean rodent Ctenomys (Rodentia, Caviomorpha): functional and morphological analysis. Biol J Linn Soc 78:85-96

Morlok WF (1983) Vergleichend und funktionell-anatomische Untersuchungen an Kopf, Hals 
und Vorderextremität subterraner Nagetiere (Mammalia, Rodentia). Cour Forsch Senckenb 64:1-237

Nevo E (1979) Adaptive convergence and divergence of subterranean mammals. Annu Rev Ecol Evol Syst 10:269-308

Nevo E (1999) Mosaic Evolution of Subterranean Mammals: Regression, Progression and Global Convergence. Oxford University Press, Oxford

Nowak RM (1999) Walker's Mammals of the World, Vol. II, 6th ed. Johns Hopkins University Press, Baltimore

Patterson BD, Upham NS (2014) A newly recognized family from the Horn of Africa, the Heterocephalidae (Rodentia: Ctenohystrica). Zool J Linn Soc 172:942-963

Renaud S, Gomes Rodrigues H, Ledevin R, Pisanu B, Chapuis J-L, Hardouin E (2015) Fast evolutionary response of house mice to anthropogenic disturbances on a sub-Antarctic island. Biol J Linn Soc 114:513-526

Rohlf FJ (1999) Shape statistics: Procrustes superimpositions and tangent spaces. J Classif $16: 197-223$

Specht M, Lebrun R, Zollikofer CPE (2007) Visualizing shape transformation between chimpanzee and human braincases. Visual Comput 23:743-751

Stein BR (2000) Morphology of subterranean rodents. In: Lacey EA, Patton JL, Cameron GN (eds) Life Underground: The Biology of Subterranean Rodents. University of Chicago Press, Chicago, pp 19-61

Šumbera R, Mazoch V, Patzenhauerová H, Lövy M, Šklíba J, Bryja J, Burda H (2012) Burrow architecture, family composition and habitat characteristics of the largest social African mole-rat: the giant mole-rat constructs really giant burrow systems. Acta Theriol 57:121-130

Tullberg T (1899) Über das System der Nagethiere, eine phylogenetische Studie. Nova Acta 
Reg Soc Sci Upsala Ser 3 18:1-514

Van Daele PAAG, Faulkes CG, Verheyen E, Adriaens D (2007) African mole-rats (Bathyergidae): a complex radiation in tropical soils. In: Begall S, Šmbera R, Schleich CE (eds) Subterranean Rodents: News from Underground. Springer-Verlag, Berlin, Heidelberg, pp 358-373

Van Daele PAAG, Herrel A, Adriaens D (2009) Biting performance in teeth-digging African mole-rats (Fukomys, Bathyergidae, Rodentia). Physiol Biochem Zool 82:40-50

Vassallo AI (1998) Functional morphology, comparative behaviour, and adaptation in two sympatric subterranean rodents, genus Ctenomys (Caviomorpha: Octodontidae). J Zool 244:415-427

Vleck D (1981) Burrow structure and foraging costs in the fossorial rodents, Thomomys bottae. Oecologia 49:391-396

Zelová J, Šumbera R, Okrouhlík J, Škliba J, Lövy M, Burda H (2011) A seasonal difference of daily energy expenditure in a free-living subterranean rodent, the silvery mole-rat (Heliophobius argenteocinereus; Bathyergidae). Comp Biochem Physiol Part A $158: 17-21$

Zelová J, Šumbera R, Sedláček F, Burda H (2007) Energetics in a solitary subterranean rodent, the silvery mole-rat, Heliophobius argenteocinereus, and allometry of RMR in African mole-rats (Bathyergidae). Comp Biochem Physiol Part A 147:412-419 


\section{Figure captions}

Fig.1 Landmarks digitized on the cranium (a, dorsal view, c, ventral view, e, lateral view) and the mandible (b, lateral view, c, occlusal view) of Heliophobius (ID13) imaged by using Xray conventional microtomographic 3D renderings. The landmarks 36 and 54, and 40 and 57 were only used for the analyses of Bathyergidae, because they were not included when the Ctenohystrica database was realized (see Hautier et al. 2012). (f) Measure of inlevers (black lines), and outlevers (grey lines) between landmarks digitized on the mandible of Heliophobius. Outlevers of cheek teeth correspond to the distance between the landmark 66 (condyle), and an approximation of the middle of the tooth using the middle point of the distance between the landmarks 62 and 63. T: Temporalis; SM: Superficial Masseter; DM: Deep Masseter; I: Incisor; CT: Cheek Teeth.
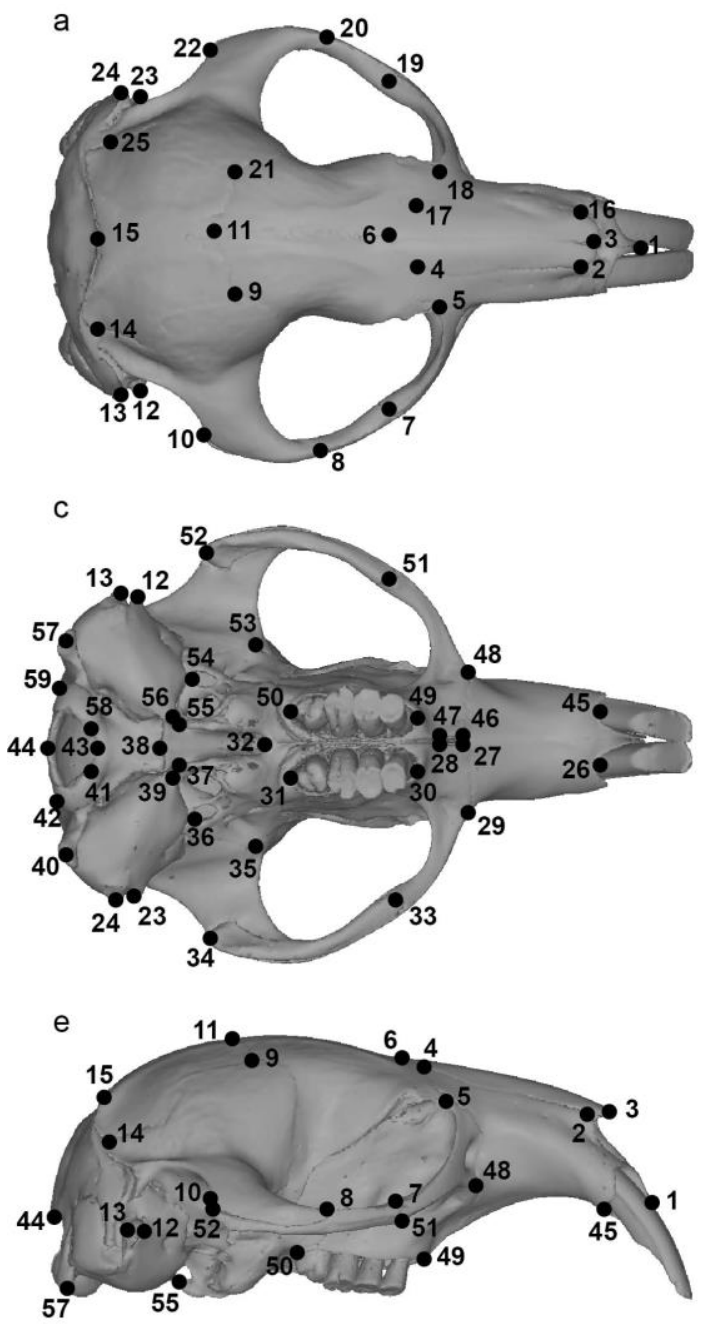

b
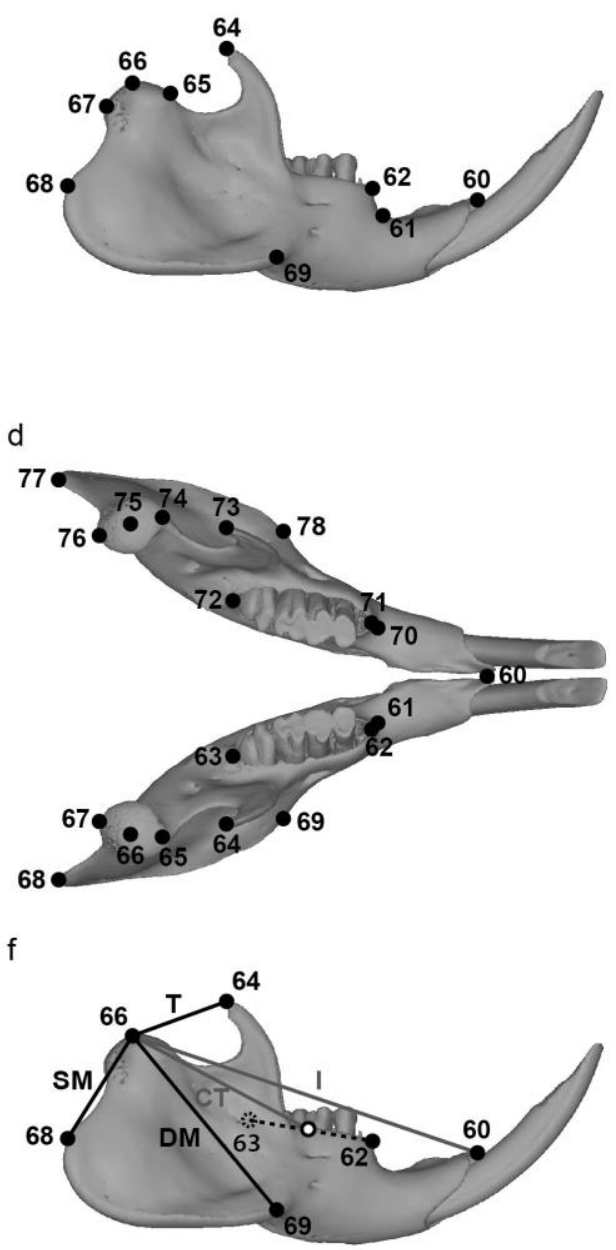
Fig.2 Principal component analyses realized on (a) crania and (b) mandibles of Ctenohystrica and associated virtual deformations on the extreme sides of each axis. Symbols used: $(\bigcirc)$ nonfossorial; $(\square)$ scratch digger; $(\Delta)$ chisel-tooth digger (Spalacopus); $(\diamond)$ both modes of digging (Ctenomys); (口) scratch digging Bathyergidae (Bathyergus); $(\Delta)$ chisel-tooth digging Bathyergidae

a
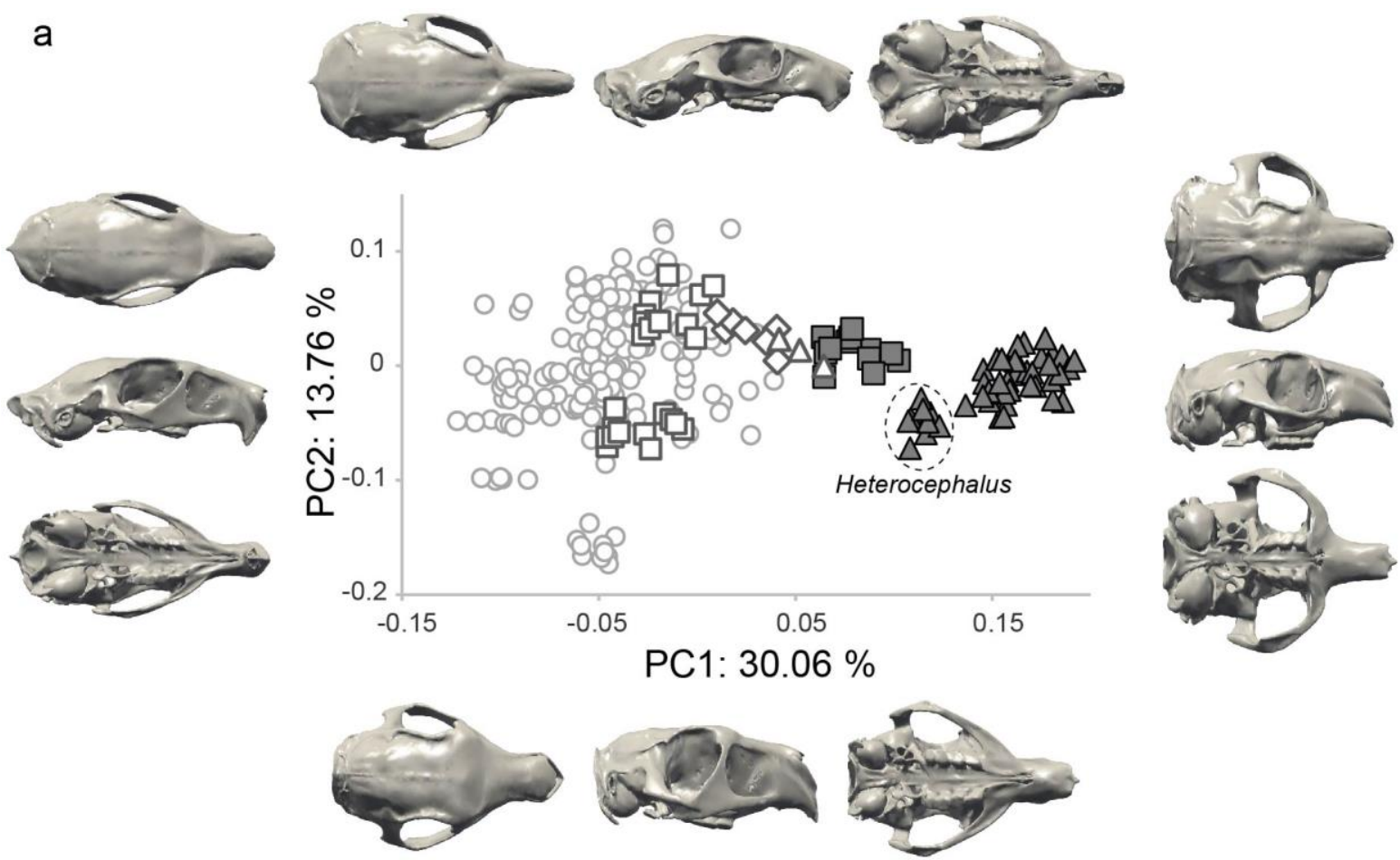

b
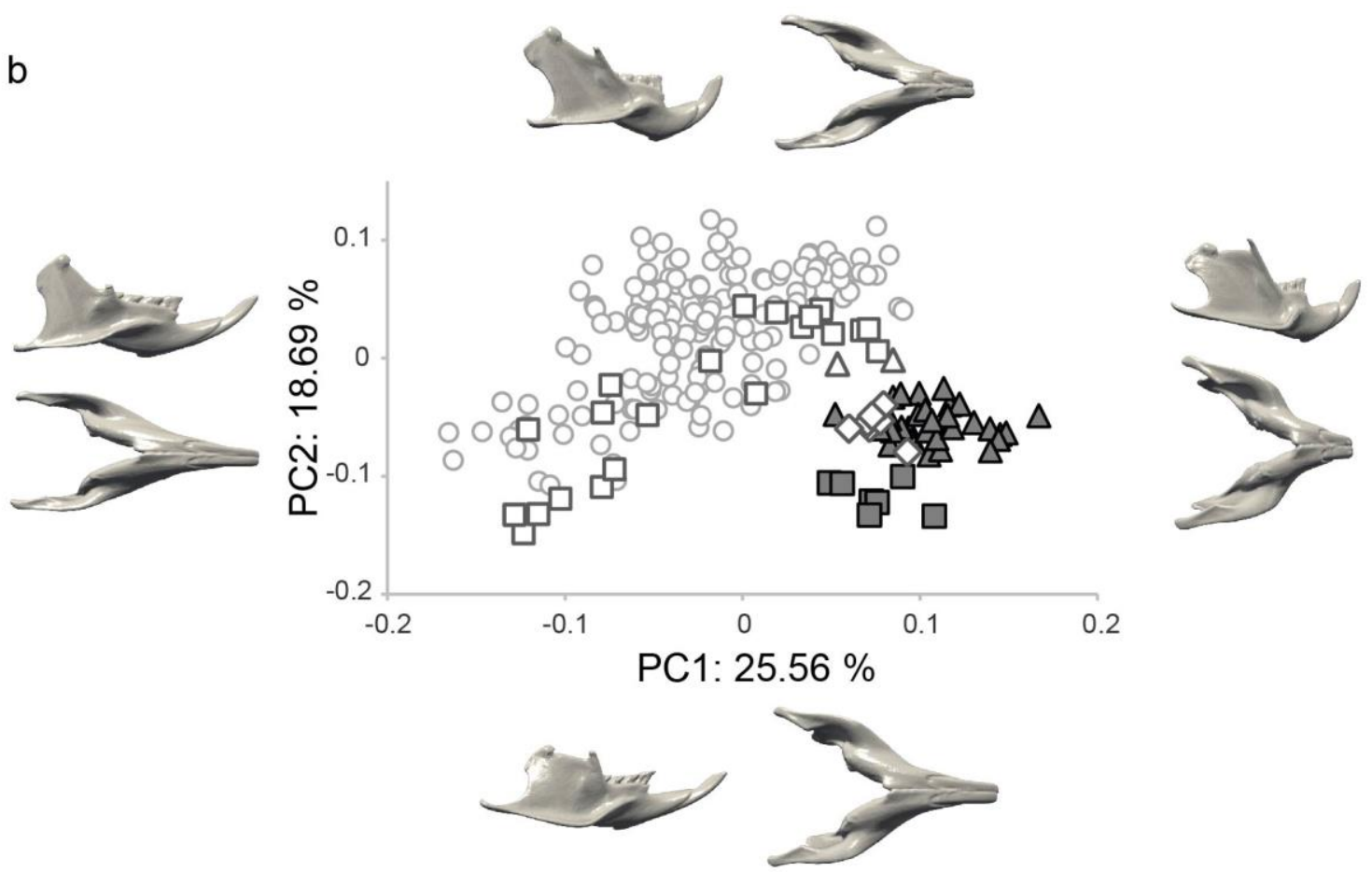
Fig.3 Regression of the first and second principal component on the centroid size of (a) crania and (b) mandibles of Ctenohystrica and associated virtual deformations. Symbols used: (०) non-fossorial; $(\square)$ scratch digger; $(\Delta)$ chisel-tooth digger (Spalacopus); $(\diamond)$ both modes of digging (Ctenomys); ( $\square$ ) scratch digging Bathyergidae (Bathyergus); ( $\Delta$ ) chisel-tooth digging Bathyergidae 

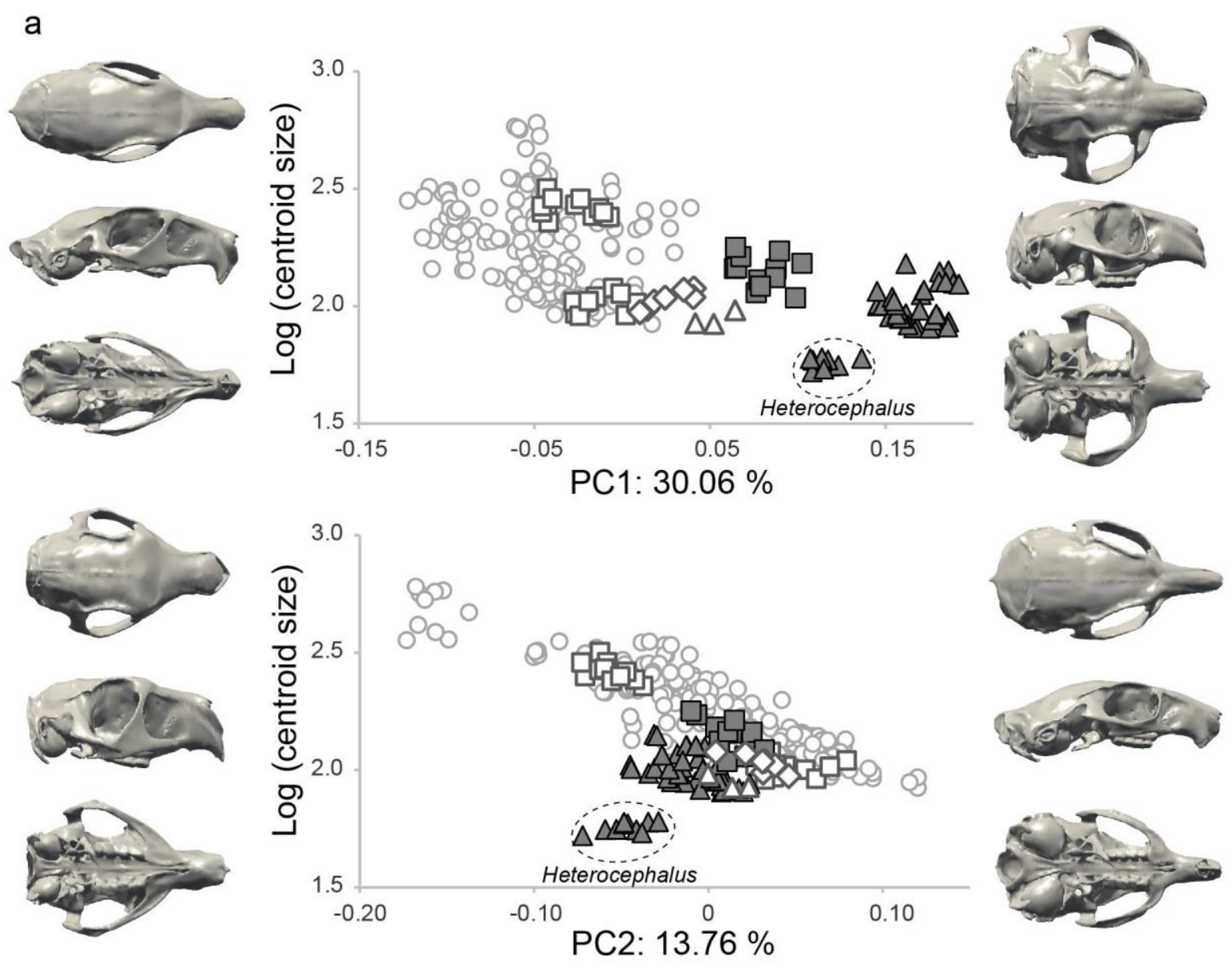

b
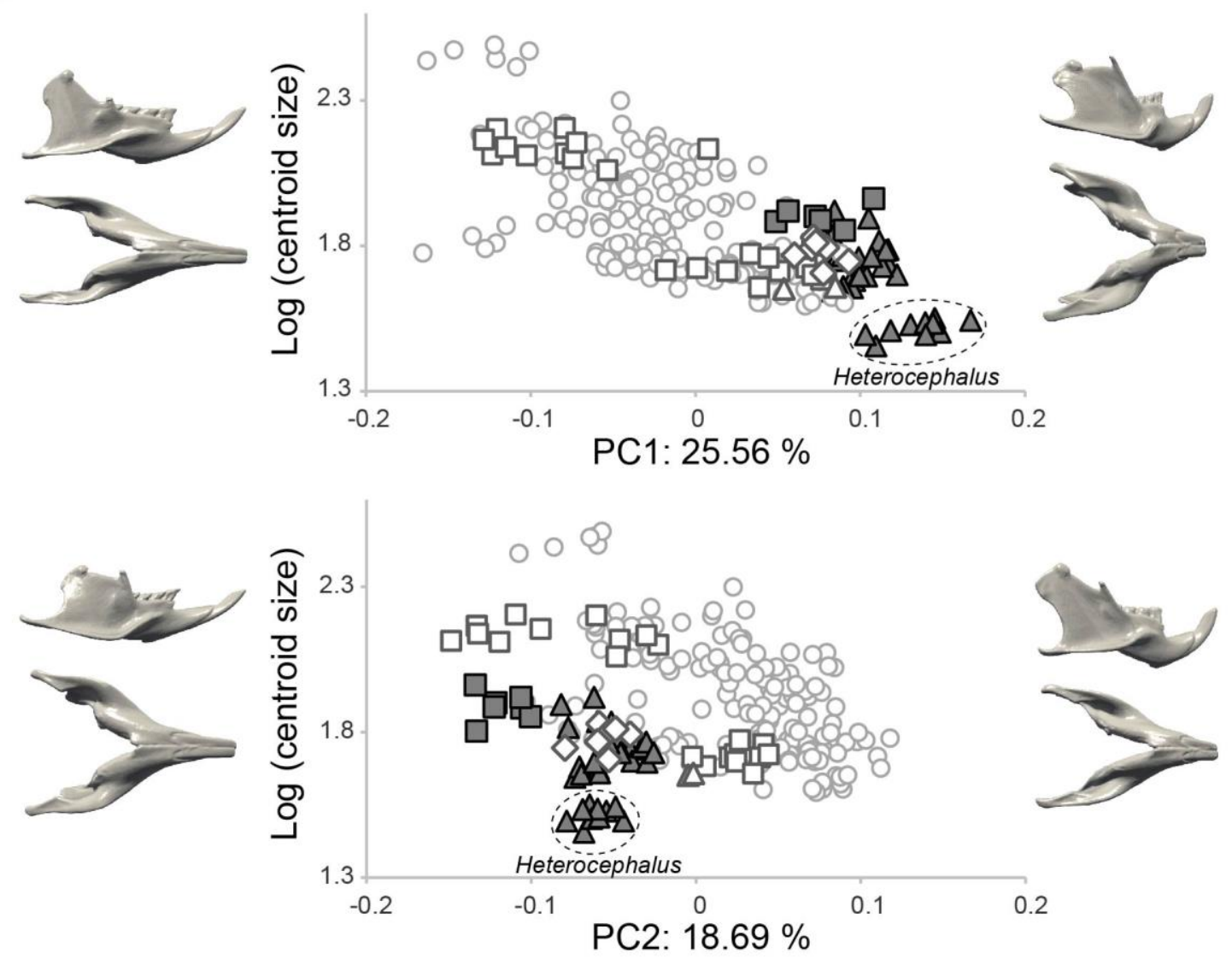
Fig.4 First two singular warp (SW) mandibular and cranial scores and associated mandibular and cranial covariation patterns for the subset of specimens for which the crania and the mandibles had been digitized. Symbols used: $(\odot)$ non-fossorial; $(\square)$ scratch digger; $(\Delta)$ chiseltooth digger (Spalacopus); ( $\diamond)$ both modes of digging (Ctenomys); ( $\square$ ) scratch digging Bathyergidae (Bathyergus); $(\Delta)$ chisel-tooth digging Bathyergidae
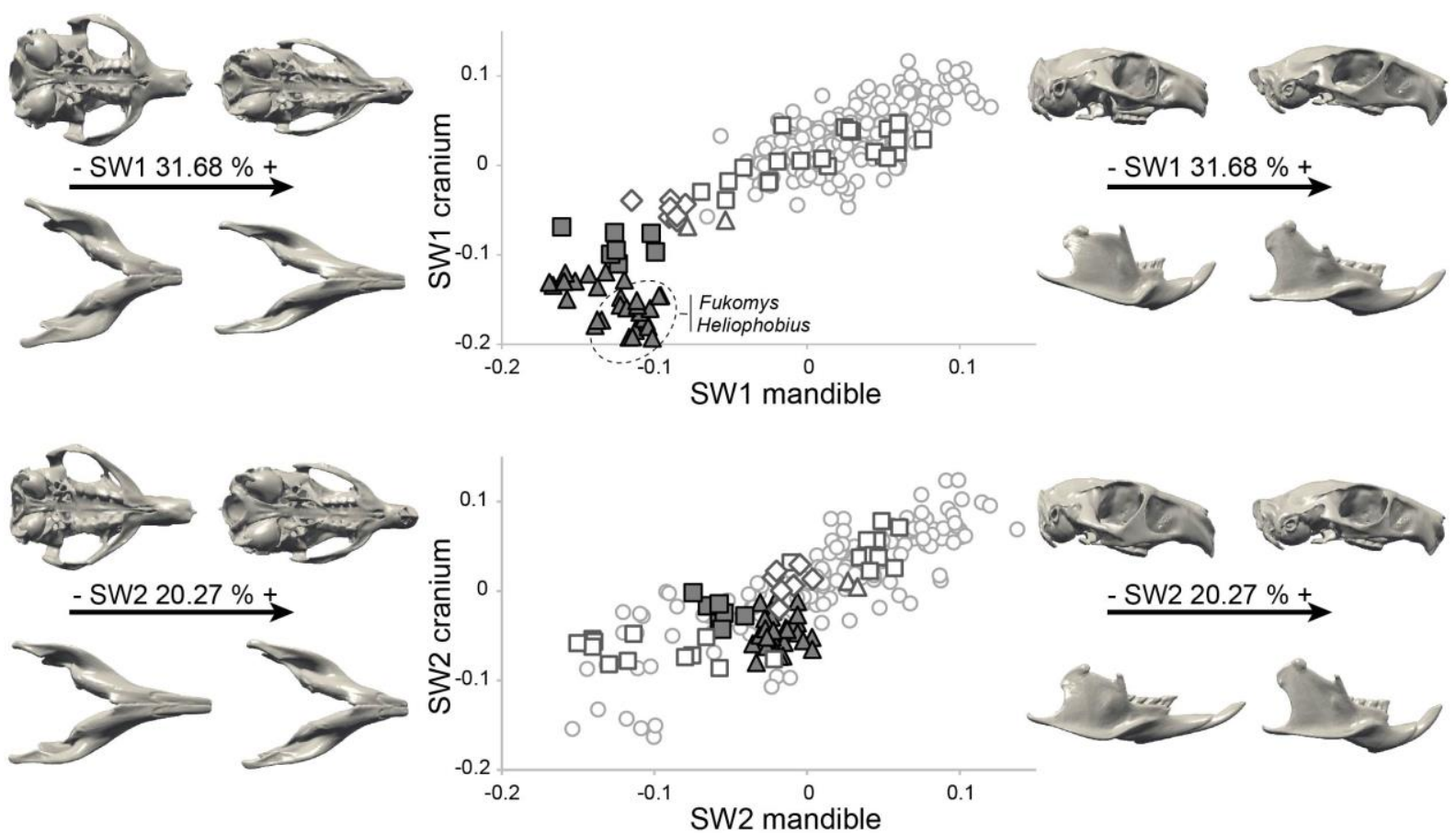
Fig.5 Histograms representing the mean inlever/outlever ratio with corresponding standard deviations for fossorial taxa and a few other Ctenohystrica. Symbols used: ( $\square$ ) non-fossorial;

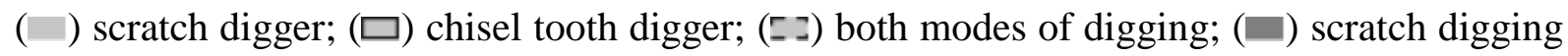
Bathyergidae; $(\square)$ chisel tooth digging Bathyergidae
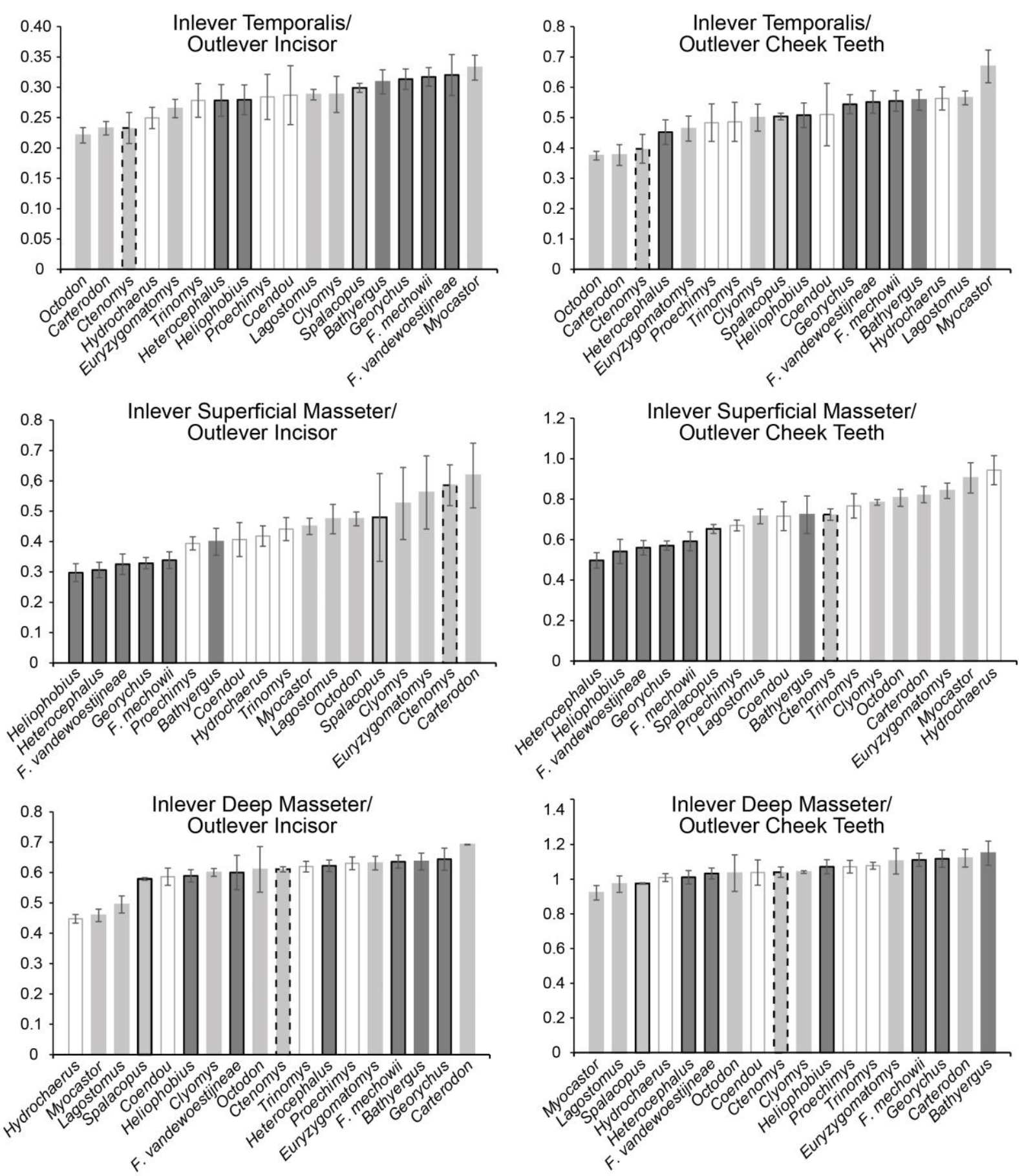
Fig.6 Principal component analyses realized on crania and mandibles of Bathyergidae, and associated virtual deformations on the extreme sides of each axis. Symbols used: (x)

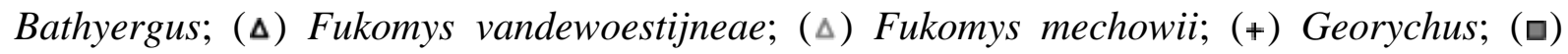
Heliophobius; ( $($ ) Heterocephalus
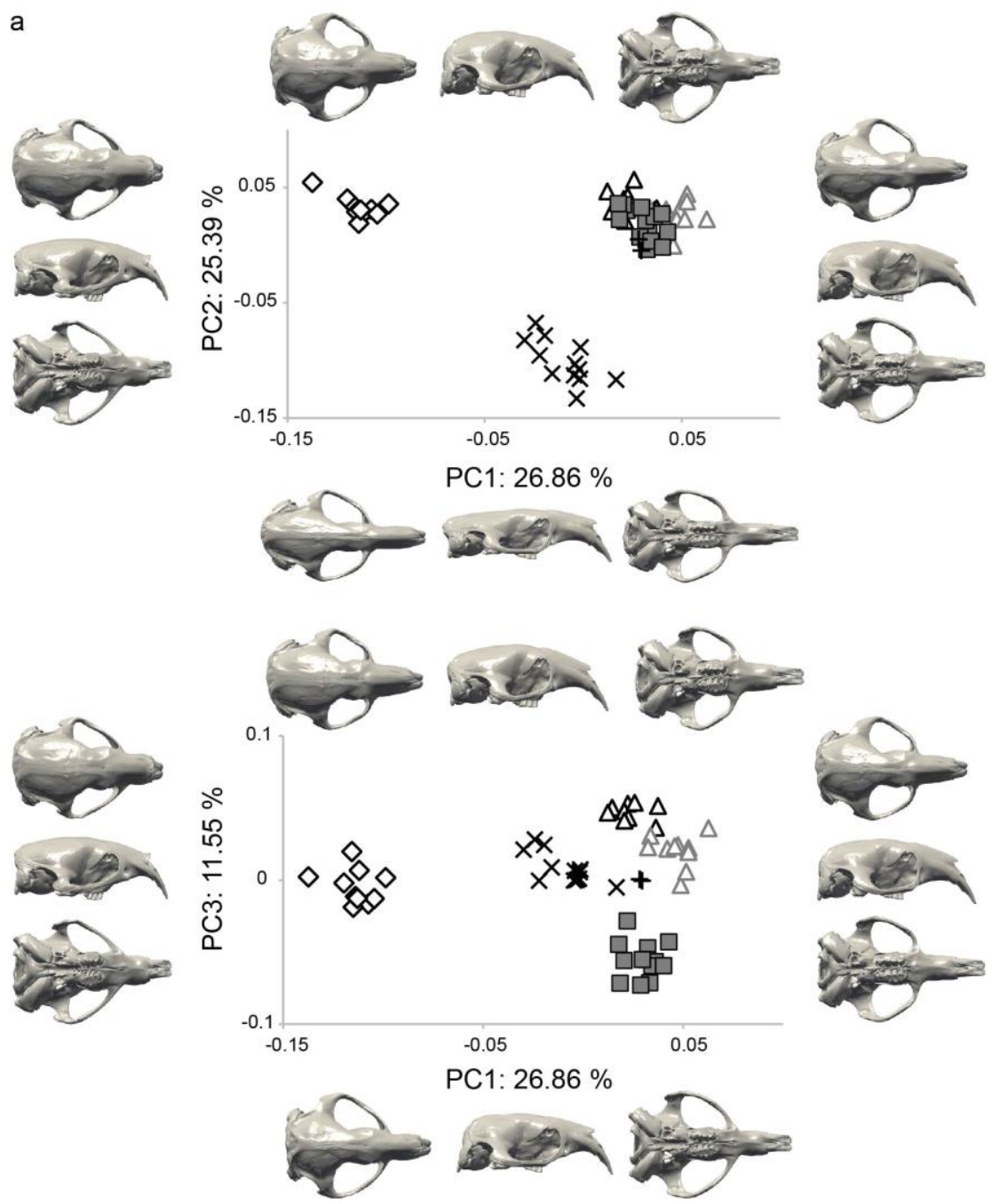

b

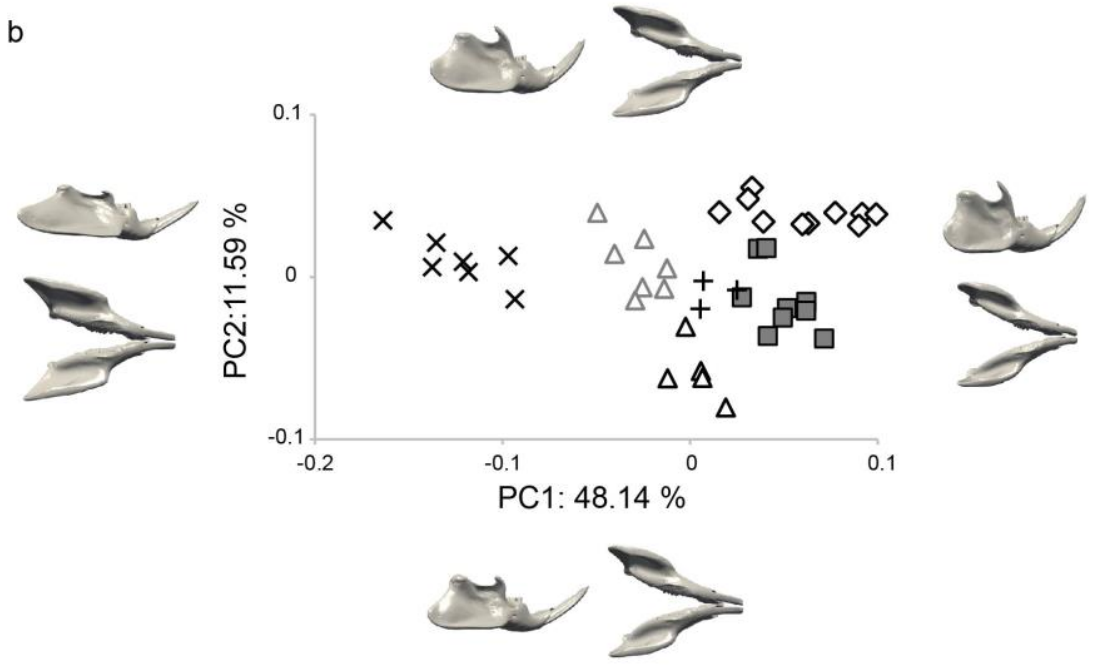


Table 1 List of analyzed taxa, material, mode of digging and foraging activity of fossorial species (in bold). *: subterranean (sensu Nevo, 1979), A: Aboveground, U: Underground. “_” means both, "()" means occasionally. Data derived mainly from Nowak (1999), and Stein (2000).

\begin{tabular}{|c|c|c|c|c|}
\hline Family & Genus & Cranium & Mandible & $\begin{array}{l}\text { Mode of digging / } \\
\text { foraging activity }\end{array}$ \\
\hline Abrocomiidae & Abrocoma & 4 & 5 & \\
\hline \multirow[t]{5}{*}{ Bathyergidae } & Bathyergus* & 12 & 7 & Scratch/U(A) \\
\hline & $\begin{array}{l}\text { Fukomys } \\
\text { vandewoestijneae* } \\
\text { / Fukomys } \\
\text { mechowii* }\end{array}$ & $10 / 10$ & $5 / 7$ & Chisel-tooth/U \\
\hline & Georychus* & 3 & 3 & Chisel-tooth/U \\
\hline & Heliophobius* & 13 & 8 & Chisel-tooth/U \\
\hline & Heterocephalus* & 10 & 10 & Chisel-tooth/U \\
\hline Capromyidae & Capromys & 4 & 4 & \\
\hline \multirow[t]{8}{*}{ Caviidae } & Cavia & 5 & 5 & \\
\hline & Caviella & 2 & 2 & \\
\hline & Dolichotis & 5 & 5 & \\
\hline & Galea & 2 & 2 & \\
\hline & Hydrochaerus & 6 & 6 & \\
\hline & Kerodon & 1 & 1 & \\
\hline & Monticavia & 2 & 2 & \\
\hline & Nanocavia & 2 & 2 & \\
\hline \multirow[t]{3}{*}{ Chinchillidae } & Chinchilla & 3 & 3 & \\
\hline & Lagidium & 5 & 5 & \\
\hline & Lagostomus & 6 & 6 & Scratch/A \\
\hline \multirow[t]{3}{*}{ Ctenodactylidae } & Ctenodactylus & 4 & 2 & \\
\hline & Felovia & 1 & 1 & \\
\hline & Massoutiera & 3 & 3 & \\
\hline Ctenomyidae & Ctenomys* & 7 & 7 & Scratch, Chisel-tooth/U-A \\
\hline Cuniculidae & Cuniculus & 9 & 9 & \\
\hline \multirow[t]{2}{*}{ Dasyproctidae } & Dasyprocta & 10 & 10 & \\
\hline & Myoprocta & 10 & 9 & \\
\hline Diatomyidae & Laonastes & 3 & 3 & \\
\hline Dinomyidae & Dinomys & 3 & 3 & \\
\hline \multirow[t]{7}{*}{ Echimyidae } & Callistomys & 1 & 0 & \\
\hline & Carterodon & 2 & 2 & Scratch/A \\
\hline & Clyomys & 2 & 2 & Scratch/A \\
\hline & Dactylomys & 2 & 2 & \\
\hline & Diplomys & 1 & 1 & \\
\hline & Echimys & 6 & 6 & \\
\hline & Euryzygomatomys & 2 & 2 & Scratch/A \\
\hline
\end{tabular}




\begin{tabular}{|c|c|c|c|c|}
\hline & Geocapromys & 2 & 2 & \\
\hline & Hoplomys & 2 & 2 & \\
\hline & Isothrix & 2 & 2 & \\
\hline & Kannabateomys & 2 & 2 & \\
\hline & Lonchothrix & 1 & 1 & \\
\hline & Makalata & 2 & 2 & \\
\hline & Mesocapromys & 2 & 2 & \\
\hline & Mesomys & 7 & 7 & \\
\hline & Myocastor & 6 & 6 & Scratch/A \\
\hline & Ollalamys & 0 & 1 & \\
\hline & Phyllomys & 2 & 2 & \\
\hline & Plagiodontia & 1 & 1 & \\
\hline & Proechimys & 18 & 15 & \\
\hline & Trichomys & 4 & 3 & \\
\hline & Trinomys & 4 & 4 & \\
\hline Erethizontidae & Chaetomys & 1 & 1 & \\
\hline & Coendou & 4 & 3 & \\
\hline & Echinoprocta & 2 & 2 & \\
\hline & Erethizon & 3 & 3 & \\
\hline & Shiggurus & 2 & 2 & \\
\hline Hystricidae & Atherurus & 5 & 5 & \\
\hline & Hystrix & 10 & 8 & \\
\hline & Trichys & 3 & 3 & \\
\hline Octodontidae & Octodon & 6 & 4 & Scratch/A \\
\hline & Octodontomys & 2 & 2 & \\
\hline & Spalacopus* & 3 & 2 & Chisel-tooth/U-A \\
\hline & Tympanoctomys & 1 & 1 & \\
\hline Petromuridae & Petromus & 4 & 3 & \\
\hline Thryonomyidae & Thryonomys & 5 & 5 & \\
\hline Number of speci & mens & 277 & 246 & \\
\hline
\end{tabular}

